Article

\title{
Sarcopenia in Patients with Rheumatic Diseases: Prevalence and Associated Risk Factors
}

\author{
Michele Barone ${ }^{1, *,+} \mathbb{D}$, Maria Teresa Viggiani ${ }^{1,+}$, Maria Grazia Anelli ${ }^{2}$, Rosalinda Fanizzi ${ }^{2}$, \\ Orsola Lorusso ${ }^{1}$, Giuseppe Lopalco ${ }^{2}$, Luca Cantarini ${ }^{3}$, Alfredo Di Leo ${ }^{1}$, Giovanni Lapadula ${ }^{2}$ \\ and Florenzo Iannone ${ }^{2}$ (D) \\ 1 Gastroenterology Unit, Department of Emergency and Organ Transplantation, University of Bari, 70124 Bari, \\ Italy; viggiani.mt@libero.it (M.T.V.); orsolalorusso@me.com (O.L.); alfredo.dileo@uniba.it (A.D.L.) \\ 2 Rheumatology Unit, Department of Emergency and Organ Transplantation, University of Bari, 70124 Bari, \\ Italy; marynelli@libero.it (M.G.A.); rosalinda.fanizzi@hotmail.it (R.F.); glopalco@hotmail.it (G.Lo.); \\ giovanni.lapadula@uniba.it (G.La.); florenzo.iannone@uniba.it (F.I.) \\ 3 Research Center of Systemic Autoinflammatory Diseases and Behçet's Disease Clinic, Department of \\ Medical Sciences, Surgery and Neurosciences, University of Siena, 53100 Siena, Italy; \\ cantariniluca@hotmail.com \\ * Correspondence: michele.barone@uniba.it; Tel.: +39-080-5593514; Fax: +39-080-5593177 \\ + These authors equally contributed to this manuscript.
}

Received: 15 November 2018; Accepted: 28 November 2018; Published: 1 December 2018

\begin{abstract}
The prevalence of sarcopenia in rheumatic diseases has been evaluated in single diseases using various diagnostic approaches, generating conflicting data on the pathogenetic mechanism(s). Herein, we evaluated both muscle mass index (MMI) and muscle strength to assess sarcopenia and presarcopenia in patients with rheumatoid arthritis (RA), psoriatic arthritis (PsA), and ankylosing spondylitis (AS). Moreover, we evaluated the possible impact of disease/patient-related characteristics, therapeutic regimens, and nutritional aspects on sarcopenia. The present study included 168 patients of both genders, aged 40-75 years. All patients underwent a nutritional evaluation, physical activity level assessment, rheumatologic evaluation, and an MMI and muscle strength assessment. The prevalence of sarcopenia was about $20 \%$ in all the three rheumatologic diseases, whereas presarcopenia was significantly different in RA, PsA and AS ( $p=0.006)$. At multivariate analysis, only age $\geq 60$ years and the presence of a disability were associated with a significantly increased risk of sarcopenia ( $p=0.006$ and $p=0.01$, respectively), while a higher C-reactive protein did not reach statistical significance. Sarcopenia is similar in RA, PsA and AS, whereas presarcopenia significantly differs in these three diseases. Disease activity/inflammation and nutritional aspects do not influence sarcopenia, while age $\geq 60$ years and the presence of a disability significantly increase the risk of sarcopenia.
\end{abstract}

Keywords: rheumatoid arthritis; psoriatic arthritis; ankylosing spondylitis; muscle mass; muscle strength; physical disability; biologic therapy

\section{Introduction}

The concept of sarcopenia was first developed to describe the age-related decrease in muscle mass in elderly human subjects ("primary sarcopenia"). Subsequently, sarcopenia has been studied in several clinical settings (usually referred to as "secondary sarcopenia"), recognizing three main pathogenic mechanisms: inflammatory activity, nutritional deficit, and physical activity impairment [1]. However, although there is a widely accepted definition of primary sarcopenia, an agreement in research and clinical practice is still lacking for secondary sarcopenia [1,2]. Currently, sarcopenia is defined by 
European working group on sarcopenia in older people (EWGSOP) criteria as an abnormally low muscle mass associated with low skeletal muscle strength and/or low physical performance, leading to an increased risk of physical disability, poor quality of life, and death [1]. Notably, recent evidence suggests that the correlation between "muscle quantity" (muscle mass) and "muscle function" (muscle strength or physical performance) is relatively weak, and, in contrast to muscle function, muscle mass has been demonstrated to be a poor predictor of functional limitation, gait speed, and also mortality [3].

In rheumatic diseases, several studies have measured the muscle mass index (MMI), without taking into consideration the assessment of muscle strength and/or physical performance [4-10]. On the other hand, three more recent studies used EWGSOP criteria for the assessment of sarcopenia [11-13]. However, the latter studies were focused on three different rheumatic diseases and used different techniques for the assessment of muscle mass (Dual energy X-ray absorptiometry (DXA) or bioelectrical impedance analysis (BIA)) and muscle function (handgrip and/or one physical performance test) [11-13], making it difficult to compare them. In addition, the data about the causes of sarcopenia and the possible beneficial effect of therapies with antibodies targeting specific immune system pathways (biological therapy) are not conclusive [11,13].

In the present study, we assessed sarcopenia and presarcopenia on the basis of EWGSOP criteria and compared, for the first time, these two conditions in three different rheumatic diseases: rheumatoid arthritis (RA), ankylosing spondylitis (AS) and psoriatic arthritis (PsA) (primary end-point). In addition, we evaluated the influence of age, sex, physical activity, nutritional intake, disease duration, disease activity, disability, and type of therapy on sarcopenia (secondary end-point).

The comparison of sarcopenia and presarcopenia in patients affected by RA, PsA, and AS led to the demonstration that the prevalence of sarcopenia is similar in the three diseases, while presarcopenia is significantly increased in PsA and AS when compared to RA. Our analysis suggests that age and disability are the only significant risk factors for sarcopenia.

\section{Patients and Methods}

\subsection{Patients Characteristics}

Caucasian rheumatologic patients included in a prospective register (ClinicalTrials.gov identifier NCT01543594) underwent a nutritional evaluation by the nutritional team of the Gastroenterology Unit from May 2015 to December 2016. Our research was carried out in compliance with the Helsinki Declaration, all patients gave their informed consent, and all procedures received the local ethics committee's approval (protocol\# 589CE).

Patients aged 40-75 years of both sexes with a diagnosis of RA, SA, and PsA were enrolled in order to evaluate the prevalence of sarcopenia and presarcopenia in these pathological conditions. The exclusion criteria were: uncertain diagnosis; obesity (the assessment of sarcopenia by anthropometry has not been validated in the presence of this condition) [14]; possible other causes of secondary sarcopenia (malnutrition, decompensated diabetes, advanced chronic kidney disease, chronic obstructive pulmonary disease, and chronic heart failure); presence of severe metacarpophalangeal joint derangement (it would be a major confounder of grip strength).

During the nutritional visit, weight, height, body mass index, (BMI), total calories and protein intake, physical activity level (PAL), MMI and muscle strength were evaluated. The rheumatologic visit involved the evaluation of disability and disease activity scores, and erythrocyte sedimentation rate (ESR) and C-reactive protein (CRP) determination. The data of diagnosis, duration of illness, current rheumatic therapy, and presence/absence of rheumatoid factor (RF) and anti-citrulline antibodies (anti-CCP $\mathrm{Ab}$ ) were obtained from outpatient medical records.

\subsection{Nutritional Evaluations}

In addition to weight, height, and BMI, a quantitative and qualitative evaluation of the dietary intake was performed as previously described, and the daily calorie and protein intake were adjusted 
for body weight [15]. PAL was obtained by calculating the ratio of total to basal daily energy expenditure (TEE/BEE). BEE was calculated using the Harris-Benedict formula and TEE was calculated using BEE and the integrated energy index (IEI). The data on the activity and occupation of all participants of the study were gathered for the entire $24 \mathrm{~h}$ to determine the IEI [16]. The measurement of MMI was based on the determination of body composition assessed by bioelectrical impedance analysis (BIA) (BIA 101, Akern srl, Pontassieve, (FI), Italy) as previously described [17]. This technique correlates well with dual-energy X-ray absorptiometry (DXA) in this clinical setting [7]. In addition, MMI was evaluated by anthropometry. The total muscle mass evaluation by anthropometry was calculated as previously described by Lee et al. [14]. MMI was obtained as the ratio of total muscle mass to height ${ }^{2}$. A handgrip dynamometer (Jamar ${ }^{\circledR}$, Sammons Preston, Bolingbrook, IL, USA) was used to determine muscle strength, as previously described [17]. The test was repeated three consecutive times, for each forearm, and the mean value was used.

\subsection{Sarcopenia Evaluation}

The diagnosis of sarcopenia was performed in the presence of both muscle mass and muscle strength reduction, while muscle mass reduction alone without muscle strength impairment was considered presarcopenia $[1,18]$. The reference values for the diagnosis of muscle mass and muscle strength reduction were: MMI $<6.75 \mathrm{~kg} / \mathrm{m}^{2}$ in women and $<10.75 \mathrm{~kg} / \mathrm{m}^{2}$ in men (associated with physical disability in subjects aged $\geq 60$ years) and handgrip strength $<20 \mathrm{~kg}$ in women and $<30 \mathrm{~kg}$ in men (associated to reduced mobility), respectively $[19,20]$.

\subsection{Disease Activity Assessment}

The disease activity was evaluated using the following scores: "disease activity score 28 (DAS 28)" [21,22], "clinical disease activity index (CDAI)", and "simplified disease activity index (SDAI)" in RA patients [23-25]; "Bath Ankylosing Spondylitis Disease Activity Index (BASDAI)" [26], "Ankylosing Spondylitis Disease Activity Score-CRP (ASDAS-CRP)", and "Ankylosing Spondylitis Disease Activity Score-ESR (ASDAS-ESR)" for AS patients [27,28]; “Disease Activity Index for Psoriatic Arthritis (DAPSA)", for PsA patients [29,30]. For the assessment of disability, the "Health assessment questionnaire (HAQ)" $[31,32]$ was used. CRP was considered pathological when the ratio between the value found in each subject and the upper normal limit was $>1$.

\subsection{Statistical Analysis}

For continuous variables, an analysis of sample distribution was performed by evaluating the symmetry with the Skewness and Kurtosis tests, and the variables were expressed as mean \pm standard deviations (SD). Statistical comparisons of two or more continuous variables with normal distribution were performed by $t$ test and ANOVA, respectively. Categorical variables were expressed as percentages and compared using the chi-square or Fisher's exact test, followed by the Bonferroni post-hoc analysis when required. The evaluation of factors associated with sarcopenia (covariates) was performed using univariate analysis, and only covariates showing a $p$ value $<0.25$ at univariate analysis were included in the multivariate logistic regression analysis. The correlation between MMI values obtained with BIA and anthropometry was performed by Pearson's correlation test. The statistical significance was set at $p<0.05$. The analyses were performed using SPSS software, version 23.0 (SPSS Inc., Chicago, IL, USA).

\section{Results}

A total of 254 subjects were examined for eligibility, and only 168 adults were enrolled (36 were excluded due to exclusion criteria or missing data).

In Table 1 we reported a comparison among demographic and clinical and therapeutic data in patients with RA, PA, and AS. 
Table 1. Demographic, clinical and therapeutic data in patients with the different rheumatic diseases analysed.

\begin{tabular}{ccccc}
\hline & $\begin{array}{c}\text { Rheumatoid } \\
\text { Arthritis }\end{array}$ & $\begin{array}{c}\text { Psoriatic } \\
\text { Arthritis }\end{array}$ & $\begin{array}{c}\text { Ankylosing } \\
\text { Spondylitis }\end{array}$ & $p$ \\
\hline N. of pts & 76 & 70 & 22 & \\
M/F & $10 / 66$ & $32 / 38$ & $14 / 8$ & $<0.001^{*}$ \\
Age & $56.5 \pm 8.8$ & $55.3 \pm 9.1$ & $51.6 \pm 8.8$ & $0.08^{+}$ \\
Body mass index (BMI) $\left(\mathrm{kg} / \mathrm{m}^{2}\right)$ & $24.9 \pm 3.2$ & $25.6 \pm 3.0$ & $24.9 \pm 2.5$ & $0.37^{+}$ \\
Caloric intake (Kcal/Kg/die) & $24.8 \pm 6.7$ & $23.7 \pm 6.8$ & $24.8 \pm 6.5$ & $0.54^{+}$ \\
Protein intake (g/Kg/die) & $0.9 \pm 0.2$ & $0.8 \pm 0.2$ & $0.9 \pm 0.2$ & $0.39^{+}$ \\
Physical activity level & $1.3 \pm 0.1$ & $1.4 \pm 0.2$ & $1.4 \pm 0.2$ & $0.02^{+}$ \\
Disease duration (years) & $10.8 \pm 8.2$ & $11.1 \pm 8.1$ & $14.5 \pm 8.4$ & $0.16^{+}$ \\
C-reactive protein (CRP) elevated (\%) & 39.7 & 7.4 & 5.2 & $<0.001^{*}$ \\
Erythrocyte sedimentation rate (ESR) elevated (\%) & 51.3 & 26.0 & 18.1 & $0.001^{*}$ \\
Biologic therapy (\%) & 65.7 & 78.5 & 86.3 & $0.07^{*}$ \\
Disability (\%) & 52.7 & 54.2 & 54.5 & $0.97^{*}$ \\
\hline
\end{tabular}

Unless specified, the data reported in the table are expressed as means \pm SD. ${ }^{*}$ By chi square; ${ }^{\dagger}$ By ANOVA.

In RA patients there was a higher prevalence of women, a lower level of physical activity, and a higher inflammatory state compared to PA and AS patients. Age, BMI, caloric/protein intake, disease duration, type of therapy and disability did not differ in the three rheumatic diseases.

Among all the patients, 124 were on treatment with biologic drugs (for $47.5 \pm 42.1$ months) and 44 with conventional Disease Modifying Anti-Rheumatic Drugs (cDMARDS). Among the patients receiving biologic therapy, $37.0 \%$ were taking etanercept, $33.8 \%$ adalimumab and $29.0 \%$ other biologic therapy (certolizumab, ustekinumab, tocilizumab, abatacept e golimumab). In addition, in $61.3 \%$ of the cases, biologic therapy was combined with cDMARDs. The patients receiving only cDMARDs had been under therapy for $31.1 \pm 32.8$ months and in most of the cases were also receiving methotrexate $(79.5 \%)$.

In the 76 patients with RA, the disease activity was assessed by CDAI, SDAI and DAS28 scores, resulting in remission in $43.4 \%, 44.7 \%$ and $47.3 \%$ of the cases, respectively. In the 70 patients with PsA, $36.7 \%$ of cases were categorized as in remission phase using the DAPSA score. In addition, in the 22 patients with AS, the use of BASDAI, ASDAS-CRP, and ASDAS-ESR detected a remission phase in $59.1 \%, 50.0 \%$ and $28.5 \%$ of the cases, respectively. Limiting the disease activity evaluation to the 19 patients with axial spondylitis, ASDAS-CRP and ASDAS-ESR recognized a remission phase in $42.1 \%$ and $38.8 \%$ of the cases, respectively.

\subsection{Prevalence of Sarcopenia and Presarcopenia}

At the beginning of the study, the MMI was evaluated by both anthropometry and BIA. However, when we performed an ad interim analysis in 103 patients, the correlation between the two techniques was moderate/optimal ( $r=0.73$ by Pearson's correlation). Therefore, we continued the study evaluating the patients' MMI only by BIA.

As shown in Figure 1, the prevalence of sarcopenia and presarcopenia in the whole cohort of patients was $20.8 \%$ and $20.2 \%$, respectively. However, when we analysed each disease separately (Figure 1), the prevalence of sarcopenia remained unchanged, while the prevalence of presarcopenia became significantly different among the three groups (10.5\% RA, 25.7\% PsA and 36.3\% AS; $p=0.006$ by chi-square test; $\mathrm{RA} \neq \mathrm{PsA} \neq \mathrm{AS}$ by Bonferroni post-hoc analysis). 


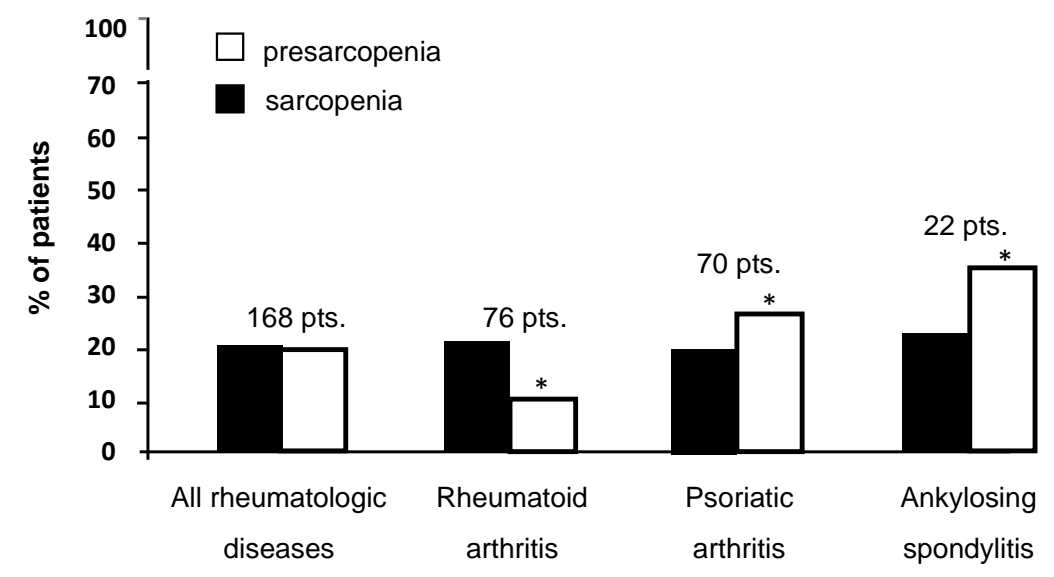

Figure 1. Prevalence of sarcopenia and pre-sarcopenia in all 168 patients. Pts. = patients. ${ }^{*} p=0.006$ by chi-square test; $\mathrm{RA} \neq \mathrm{PsA} \neq \mathrm{AS}$ by Bonferroni post-hoc analysis.

\subsection{Factors Associated with Sarcopenia in Rheumatologic Diseases}

At univariate analysis, the risk of sarcopenia increased in patients aged $\geq 60$ years compared to those aged $<60$ years (OR $=4.3 ; 95 \%$ CI: 2.0-9.6, $p<0.001$ ). An increased risk of sarcopenia was also observed in patients with higher CRP and in patients with disabilities (OR $=3.2 ; 95 \%$ CI: $1.2-8.3$, $p=0.01$ and $\mathrm{OR}=4.5 ; 95 \%$ CI: 1.8-11.2, $p=0.001$, respectively). The type of rheumatic disease, gender, calorie and protein intake, PAL, biological treatment, ESR and the duration of disease were not associated with an increased risk of sarcopenia.

At multivariate analysis (Table 2), only age $\geq 60$ years and the presence of a disability were associated with an increased risk of sarcopenia $(\mathrm{OR}=3.3 ; \mathrm{CI} 1.4-7.7, p=0.005 ; \mathrm{OR}=3.0 ; 95 \%$ CI 1.2-7.9, $p=0.01$, respectively), while a higher CRP value almost reached statistical significance $(p=0.07)$.

Table 2. Variables associated with sarcopenia.

\begin{tabular}{|c|c|c|c|c|c|}
\hline \multirow{2}{*}{ Variable } & \multirow{2}{*}{$\begin{array}{l}\text { N. of Patients with } \\
\text { Sarcopenia/Tot. (\%) }\end{array}$} & \multicolumn{2}{|c|}{ Univariate } & \multicolumn{2}{|c|}{ Multivariate } \\
\hline & & OR $(95 \% \mathrm{CI})$ & $p$ & OR $(95 \% \mathrm{CI})$ & $p$ \\
\hline Rheumatoid arthritis (RA) & $16 / 76(21.0)$ & ref. & & ref. & \\
\hline Psoriatic arthritis (PsA) & $14 / 70(20.0)$ & $0.9(0.4-2.0)$ & 0.87 & $1.1(0.4-2.7)$ & 0.79 \\
\hline Ankylosing spondylitis (AS) & $5 / 22(22.7)$ & $1.1(0.3-3.4)$ & 0.86 & $1.8(0.5-6.7)$ & 0.33 \\
\hline \multicolumn{6}{|l|}{ Gender } \\
\hline Female & $20 / 112(17.8)$ & ref. & & & \\
\hline Male & $15 / 56(26.7)$ & $1.6(0.7-3.6)$ & 0.18 & & \\
\hline \multicolumn{6}{|l|}{ Age (years) } \\
\hline$<60$ & $13 / 109(11.9)$ & ref. & & ref. & \\
\hline$\geq 60$ & $22 / 59(37.2)$ & $4.3(2.0-9.6)$ & $<0.001$ & $3.3(1.4-7.7)$ & 0.005 \\
\hline Calorie intake $^{\mathrm{a}}$ & - & $1.0(0.9-1.0)$ & 0.19 & & \\
\hline Protein intake ${ }^{b}$ & - & $2.1(0.5-8.9)$ & 0.28 & & \\
\hline Physical activity level (PAL) ${ }^{c}$ & - & $0.2(0.02-3.5)$ & 0.32 & & \\
\hline Disease duration $\mathrm{d}$ & - & $1.0(0.9-1.0)$ & 0.37 & & \\
\hline \multicolumn{6}{|l|}{ C-reactive protein $(\mathrm{CRP})$ * } \\
\hline normal & 26/137 (18.9) & ref. & & ref. & \\
\hline elevated & $9 / 21(42.8)$ & $3.2(1.2-8.3)$ & 0.01 & $2.6(0.8-7.8)$ & 0.07 \\
\hline \multicolumn{6}{|c|}{ Erythrocyte sedimentation rate (ESR) ** } \\
\hline normal & $18 / 105(17.1)$ & ref. & & & \\
\hline elevated & $16 / 60(26.6)$ & $1.7(0.8-3.7)$ & 0.14 & & \\
\hline \multicolumn{6}{|l|}{ Biologic therapy } \\
\hline no & 6/44 (13.6) & ref. & & & \\
\hline yes & $29 / 124(23.3)$ & $1.9(0.7-5.0)$ & 0.17 & & \\
\hline \multicolumn{6}{|l|}{ Disability } \\
\hline no & $7 / 77(9.0)$ & ref. & & ref. & \\
\hline yes & $28 / 89(31.4)$ & $4.5(1.8-11.2)$ & 0.001 & $3.0(1.2-7.9)$ & 0.01 \\
\hline
\end{tabular}

$\mathrm{OR}=$ odd ratio; ref. $=$ reference value. ${ }^{\text {a }} 25.7 \pm 7.3 \mathrm{vs.} 24.0 \pm 6.6 \mathrm{kcal} / \mathrm{kg}$ in sarcopenic and non-sarcopenic patients, respectively; ${ }^{\mathrm{b}} 1.0 \pm 0.3 \mathrm{vs} .0 .9 \pm 0.3 \mathrm{~g} / \mathrm{kg}$ in sarcopenic and non-sarcopenic patients, respectively; ${ }^{\mathrm{c}} 1.3 \pm 0.1 \mathrm{vs}$. $1.3 \pm 0.2$ in sarcopenic and non-sarcopenic patients, respectively; ${ }^{\mathrm{d}} 13.4 \pm 9.8 \mathrm{vs} .10 .9 \pm 7.7$ years in sarcopenic and non-sarcopenic patients, respectively; ${ }^{*}$ CRP in the 9 patients with sarcopenia was $2.6 \pm 2.5$ times higher compared to upper normal limit (see also Materials and Methods); ${ }^{* *}$ Elevated ESR in the 16 patients with sarcopenia was $2.8 \pm 1.1$ times higher compared to upper normal limit (see also Materials and Methods). 
Surprisingly, at the univariate analysis, the patients undergoing biologic therapy had a higher percentage of sarcopenia without reaching statistical significance. Therefore, we compared patients with and without biologic therapy on the basis of the risk factors for sarcopenia (age, disability). Our results demonstrated that these patients have a higher prevalence of disability, which is an expression of a more severe/advanced disease ( $p=0.04$, by chi-square, $\left.r_{\mathrm{phi}}=-0.15 ; r^{2}=0.02\right)$. On the other hand, there was no difference concerning age.

We also evaluated the prevalence of sarcopenia in all rheumatologic patients on the basis of the different disease activity scores. When comparing patients with disease activity to patients in remission, we found no difference between the two groups, using all appropriate scores. Similarly, RF and/or anti-CCP Ab were not associated with sarcopenia in RA. On the other hand, in AS, using the BASDAI, all the 12 patients in remission did not show sarcopenia, while the remaining 10 patients with active disease were $50 \%$ sarcopenic and $50 \%$ non-sarcopenic $\left(p=0.001\right.$, by chi-square, $r_{\text {phi }}=0.55$; $r^{2}=0.30$ ). This association was not found when ASDAS-CRP and ASDAS-ESR were used.

\section{Discussion}

To our knowledge, the evaluation of muscle mass reduction in rheumatic diseases has been previously assessed using three different approaches: (1) the comparison of MMI in patients via ageand sex-matched controls [4,6,7,10]; (2) the use of an MMI cut-off adopted to identify the primary sarcopenia $[9,11-13] ; 3)$ and the use of the free fat mass index of the general population, stratified for age and sex, as reference value $[5,8,33]$. In the present study, we used MMI cut-offs adopted to identify the primary sarcopenia [1], for two reasons: the comparison of MMI in patients vs. age- and sex-matched controls cannot be routinely used for the diagnosis of sarcopenia, and the free fat mass index is not specific for muscle mass. In addition, using the same methodologic approach including both MMI and muscle strength, we compared, for the first time, the prevalence of sarcopenia in RA, AS and PsA.

We found a similar prevalence of sarcopenia (about 20\%) in all three rheumatic diseases, since the only two factors significantly influencing this condition, i.e. age and disability, were similar in RA, AS and PsA (Table 1). These findings apparently differ from the data reported in a recent study of Asian patients with RA, showing a higher prevalence of sarcopenia (37.1\%) using the same methodologic approach [13]. However, the patients enrolled in this study were older compared to our patients (median age 65 (54.3-72.0) years vs. 56 (48.0-62.2)), and 1/3 were malnourished (we excluded all subjects with malnutrition, since this condition is recognized as one of the main causes of sarcopenia $[34,35])$. Another recent study of North African patients with AS [11] showed a higher prevalence of sarcopenia (34.3\%), using a different methodologic approach (DXA and handgrip strength or physical performance test) and including an undetermined number of malnourished patients. The only study evaluating the prevalence of sarcopenia in patients with PsA estimated it to be about $13.7 \%$. This study was conducted presumably in Caucasian patients and used the appendicular lean body mass index instead of MMI for the assessment of sarcopenia [12].

We observed a prevalence $(10.5 \%)$ of presarcopenia in RA. This finding was similar to that reported by a Torii et al. (11.9\%) using our methodologic approach [13]. On the other hand, we found a prevalence of $36.3 \%$ in AS, while a previous study found a higher value (50.4\%) [11] using another methodologic approach. To our knowledge, the present study is the first to assess the prevalence of presarcopenia in PsA, which was $25.7 \%$. On the basis of our finding, presarcopenia in PsA and AS patients was 2.5 and 3.6 times higher compared to RA, probably because males are more exposed to the risk of presarcopenia [36], and in our cohort RA patients were almost exclusively females, while the percentage of males significantly increased in PsA and even more in AS (Table 1).

The secondary endpoint of our study was the evaluation of putative risk factors associated with sarcopenia. Although patients with the different rheumatic diseases were significantly different for sex, physical activity and inflammatory status (Table 1), both at univariate and multivariate analysis, the type of disease did not influence the risk of sarcopenia. When we analyzed other possible risk 
factors, at multivariate analysis, only age $\geq 60$ years and the presence of a disability significantly influenced sarcopenia, while the CPR almost reached statistical significance. To further evaluate the role of inflammation in the pathogenesis of sarcopenia, in addition to previous analyses, we evaluated the multiple disease activity scores specific for each rheumatologic disease. DAS 28, CDAI, SDAI, DAPSA, ASDAS-CRP and ASDAS-ESR were not associated with sarcopenia. These findings were in agreement with those previously reported by others using DAS-28 in RA patients [13]. The only disease activity index that we found associated with sarcopenia was the BASDAI, which is the only score exclusively based on subjective patients' evaluations. This association, which we observed in both genders, was in agreement with previous data reported in men [11].

A final comment concerns our finding on the lack of a protective effect of biologic therapy against sarcopenia, in contrast with the data reported in AR patients [13]. One possible explanation comes from the inclusion of all patients with rheumatic diseases in our analysis, comprising patients with AS, in whom sarcopenia is not influenced by biologic therapy [11]. However, the fact remains that our patients undergoing biologic therapy showed a higher prevalence of disability, which is per se a significant risk factor for sarcopenia.

Our study suffers some limitations: (1) the data on the prevalence of sarcopenia were from a single centre; however, our patients were from a vast area of Southern Italy, and their number was comparable to those reported in other studies $[4,5,7,8]$; (2) we did not have a sex- and age-matched control population; however, to establish reliable reference cut-offs stratified by gender and age, it is necessary to perform large population studies, an aspect that goes beyond the aim of the present study; (3) the evaluation of inflammatory activity was based on disease scores and biochemical indexes of inflammation and not on the assessment of pro-inflammatory cytokines; (4) our results cannot apply to obese patients.

\section{Conclusions}

We compared, for the first time, the prevalence of sarcopenia in male and female patients affected by RA, PsA and AS, demonstrating that its value is similar in the three diseases. On the other hand, presarcopenia was shown to significantly increase in PsA and AS compared to RA. Our analysis suggests that the only parameters associated with the development of sarcopenia are age and disability, while disease activity seems to have a lower influence on the risk of sarcopenia.

Author Contributions: M.B., M.T.V. and F.I. designed research; M.G.A., R.F. and O.L. conducted the data from patients; L.C., G.Lo. and M.T.V. analyzed data and performed statistical analysis; M.B. and M.T.V. analysed the data and wrote the manuscript; M.B., A.D.L., and G.La. had primary responsibility for final content. All authors read and approved the final manuscript.

Conflicts of Interest: The authors declare no conflicts of interest.

\section{References}

1. Cruz-Jentoft, A.J.; Baeyens, J.P.; Bauer, J.M.; Boirie, Y.; Cederholm, T.; Landi, F.; Martin, F.C.; Michel, J.P.; Rolland, Y.; Schneider, S.M.; et al. Sarcopenia: European consensus on definition and diagnosis: Report of the European Working Group on Sarcopenia in Older People. Age Ageing 2010, 39, 412-423. [CrossRef] [PubMed]

2. Barone, M.; Viggiani, M.T.; Avolio, A.W.; Iannone, A.; Rendina, M.; Di Leo, A. Obesity as predictor of postoperative outcomes in liver transplant candidates: Review of the literature and future perspectives. Dig. Liver Dis. 2017, 49, 957-966. [CrossRef] [PubMed]

3. Baracos, V.; Caserotti, P.; Earthman, C.P.; Fields, D.; Gallagher, D.; Hall, K.D.; Heymsfield, S.B.; Müller, M.J.; Rosen, A.N.; Pichard, C.; et al. Advances in the science and application of body composition measurement. J. Parenter. Enteral Nutr. 2012, 36, 96-107. [CrossRef] [PubMed]

4. Giles, J.T.; Ling, S.M.; Ferrucci, L.; Bartlett, S.J.; Andersen, R.E.; Towns, M.; Muller, D.; Fontaine, K.R.; Bathon, J.M. Abnormal body composition phenotypes in older rheumatoid arthritis patients: Association with disease characteristics and pharmacotherapies. Arthritis Rheum. 2008, 59, 807-815. [CrossRef] [PubMed] 
5. Dao, H.H.; Do, Q.T.; Sakamoto, J. Abnormal body composition phenotypes in Vietnamese women with early rheumatoid arthritis. Rheumatology 2011, 50, 1250-1258. [CrossRef] [PubMed]

6. Aguiar, R.; Sequeira, J.; Meirinhos, T.; Ambrósio, C.; Barcelos, A. SARCOSPA-Sarcopenia in spondyloarthritis patients. Acta Reumatol. Port. 2014, 39, 322-326.

7. Doğan, S.C.; Hizmetli, S.; Hayta, E.; Kaptanoğlu, E.; Erselcan, T.; Güler, E. Sarcopenia in women with rheumatoid arthritis. Eur. J. Rheumatol. 2015, 2, 57-61. [CrossRef]

8. Elkan, A.C.; Engvall, I.L.; Cederholm, T.; Hafström, I. Rheumatoid cachexia, central obesity and malnutrition in patients with low-active rheumatoid arthritis: Feasibility of anthropometry, Mini Nutritional Assessment and body composition techniques. Eur. J. Nutr. 2009, 48, 315-322. [CrossRef]

9. Ngeuleu, A.; Allali, F.; Medrare, L.; Madhi, A.; Rkain, H.; Hajjaj-Hassouni, N. Sarcopenia in rheumatoid arthritis: Prevalence, influence of disease activity and associated factors. Rheumatol. Int. 2017, 37, 1015-1020. [CrossRef]

10. Tournadre, A.; Pereira, B.; Dutheil, F.; Giraud, C.; Courteix, D.; Sapin, V.; Frayssac, T.; Mathieu, S.; Malochet-Guinamand, S.; Soubrier, M. Changes in body composition and metabolic profile during interleukin 6 inhibition in rheumatoid arthritis. J. Cachexia Sarcopenia Muscle 2017, 8, 639-646. [CrossRef]

11. El Maghraoui, A.; Ebo'o, F.B.; Sadni, S.; Majjad, A.; Hamza, T.; Mounach, A. Is there a relation between pre-sarcopenia, sarcopenia, cachexia and osteoporosis in patients with ankylosing spondylitis? BMC Musculoskelet Disord. 2016, 17, 268. [CrossRef] [PubMed]

12. Krajewska-Włodarczyk, M.; Owczarczyk-Saczonek, A.; Placek, W. Changes in body composition and bone mineral density in postmenopausal women with psoriatic arthritis. Reumatologia 2017, 55, 215-221. [CrossRef] [PubMed]

13. Torii, M.; Hashimoto, M.; Hanai, A.; Fujii, T.; Furu, M.; Ito, H.; Uozumi, R.; Hamaguchi, M.; Terao, C.; Yamamoto, W.; et al. Prevalence and factors associated with sarcopenia in patients with rheumatoid arthritis. Mod. Rheumatol. 2018, 11, 1-7. [CrossRef] [PubMed]

14. Lee, R.C.; Wang, Z.; Heo, M.; Ross, R.; Janssen, I.; Heymsfield, S.B. Total-body skeletal muscle mass: Development and cross-validation of anthropometric prediction models. Am. J. Clin. Nutr. 2000, 72, $796-803$. [CrossRef] [PubMed]

15. Barone, M.; Della Valle, N.; Rosania, R.; Facciorusso, A.; Trotta, A.; Cantatore, F.P.; Falco, S.; Pignatiello, S.; Viggiani, M.T.; Amoruso, A.; et al. A comparison of the nutritional status between adult celiac patients on a long-term, strictly gluten-free diet and healthy subjects. Eur. J. Clin. Nutr. 2016, 70, 23-27. [CrossRef] [PubMed]

16. Human Energy Requirements: Report of a Joint FAO/WHO/UNU Expert Consultation. Available online: http:/ / www.fao.org/3/a-y5686e.pdf (accessed on 5 November 2018).

17. Viggiani, M.T.; Lorusso, O.; Natalizio, F.; Principi, M.; Di Leo, A.; Barone, M. Influence of chemotherapy on total energy expenditure in patients with gastrointestinal cancer: A pilot study. Nutrition 2017, 42, 7-11. [CrossRef] [PubMed]

18. Alkan Melikoğlu, M. Presarcopenia and its impact on disability in female patients with rheumatoid arthritis. Arch. Rheumatol. 2017, 32, 53-59. [CrossRef]

19. Janssen, I.; Baumgartner, R.N.; Ross, R.; Rosenberg, I.H.; Roubenoff, R. Skeletal muscle cutpoints associated with elevated physical disability risk in older men and women. Am. J. Epidemiol. 2004, 159, 413-421. [CrossRef]

20. Lauretani, F.; Russo, C.R.; Bandinelli, S.; Bartali, B.; Cavazzini, C.; Di Iorio, A.; Corsi, A.M.; Rantanen, T.; Guralnik, J.M.; Ferrucci, L. Age-associated changes in skeletal muscles and their effect on mobility: An operational diagnosis of sarcopenia. J. Appl. Physiol. 2003, 95, 1851-1860. [CrossRef]

21. Smolen, J.S.; Breedveld, F.C.; Eberl, G.; Jones, I.; Leeming, M.; Wylie, G.L.; Kirkpatrick, J. Validity and reliability of the twenty-eightjoint count for the assessment of rheumatoid arthritis activity. Arthritis Rheum. 1995, 38, 38-43. [CrossRef]

22. Prevoo, M.L.; van't Hof, M.A.; Kuper, H.H.; van Leeuwen, M.A.; van de Putte, L.B.; van Riel, P.L. Modified disease activity scores that include twenty-eight-joint counts. Development and validation in a prospective longitudinal study of patients with rheumatoid arthritis. Arthritis Rheum. 1995, 38, 44-48. [CrossRef] [PubMed] 
23. Smolen, J.S.; Breedveld, F.C.; Schiff, M.H.; Kalden, J.R.; Emery, P.; Eberl, G.; van Riel, P.L.; Tugwell, P. A simplified disease activity index for rheumatoid arthritis for use in clinical practice. Rheumatology 2003, 42, 244-257. [CrossRef]

24. Aletaha, D.; Smolen, J.S. The definition and measurement of disease modification in inflammatory rheumatic diseases. Rheum. Dis. Clin. N. Am. 2006, 32, 9-44. [CrossRef]

25. Aletaha, D.; Smolen, J.S. The Simplified Disease Activity Index (SDAI) and Clinical Disease Activity Index (CDAI) to monitor patients in standard clinical care. Best Pract. Res. Clin. Rheumatol. 2007, 21, 663-675. [CrossRef] [PubMed]

26. Garrett, S.; Jenkinson, T.; Kennedy, L.G.; Whitelock, H.; Gaisford, P.; Calin, A. A new approach to defining disease status in ankylosing spondylitis: The Bath Ankylosing Spondylitis Disease Activity Index. J. Rheumatol. 1994, 21, 2286-2291. [PubMed]

27. Lukas, C.; Landewé, R.; Sieper, J.; Dougados, M.; Davis, J.; Braun, J.; van der Linden, S.; van der Heijde, D. Development of an ASAS-endorsed disease activity score (ASDAS) in patients with ankylosing spondylitis. Ann. Rheum. Dis. 2009, 68, 18-24. [CrossRef] [PubMed]

28. Machado, P.; Landewé, R.; Lie, E.; Kvien, T.K.; Braun, J.; Baker, D.; van der Heijde, D. Ankylosing Spondylitis Disease Activity Score (ASDAS): Defining cut-off values for disease activity states and improvement scores. Ann. Rheum. Dis. 2011, 70, 47-53. [CrossRef]

29. Eberl, G.; Studnicka-Benke, A.; Hitzelhammer, H.; Gschnait, F.; Smolen, J.S. Development of a disease activity index for the assessment of reactive arthritis (DAREA). Rheumatology 2000, 39, 148-155. [CrossRef]

30. Schoels, M.; Aletaha, D.; Funovits, J.; Kavanaugh, A.; Baker, D.; Smolen, J.S. Application of the DAREA/DAPSA score for assessment of disease activity in psoriatic arthritis. Ann. Rheum. Dis. 2010, 69, 1441-1447. [CrossRef]

31. Fries, J.F.; Spitz, P.; Kraines, R.G.; Holman, H.R. Measurement of patient outcome in arthritis. Arthritis Rheum. 1980, 23, 137-145. [CrossRef]

32. Ranza, R.; Marchesoni, A.; Calori, G.; Bianchi, G.; Braga, M.; Canazza, S.; Canesi, B.; Fumagalli, M.; Mastaglio, C.; Mathieu, A.; et al. The Italian version of the Functional Disability Index of the Health Assessment Questionnaire. A reliable instrument for multicenter studies on rheumatoid arthritis. Clin. Exp. Rheumatol. 1993, 11, 123-128.

33. Santos, M.J.; Vinagre, F.; Canas da Silva, J.; Gil, V.; Fonseca, J.E. Body composition phenotypes in systemic lupus erythematosus and rheumatoid arthritis: A comparative study of Caucasian female patients. Clin. Exp. Rheumatol. 2011, 29, 470-476. [PubMed]

34. Kim, J.S.; Wilson, J.M.; Lee, S.R. Dietary implications on mechanisms of sarcopenia: Roles of protein, amino acids and antioxidants. J. Nutr. Biochem. 2010, 21, 1-13. [CrossRef]

35. Verlaan, S.; Aspray, T.J.; Bauer, J.M.; Cederholm, T.; Hemsworth, J.; Hill, T.R.; McPhee, J.S.; Piasecki, M.; Seal, C.; Sieber, C.C.; et al. Nutritional status, body composition, and quality of life in community-dwelling sarcopenic and non-sarcopenic older adults: A case-control study. Clin. Nutr. 2017, 36, 267-274. [CrossRef] [PubMed]

36. Baker, J.F.; Long, J.; Ibrahim, S.; Leonard, M.B.; Katz, P. Are men at greater risk of lean mass deficits in rheumatoid arthritis? Arthritis Care Res. 2015, 67, 112-119. [CrossRef] [PubMed]

(c) 2018 by the authors. Licensee MDPI, Basel, Switzerland. This article is an open access article distributed under the terms and conditions of the Creative Commons Attribution (CC BY) license (http://creativecommons.org/licenses/by/4.0/). 